\title{
ICT-Based Identification and Characterisation of Small Reservoirs in the Limpopo River Basin in Zimbabwe
}

\author{
Patrick-M. Bahal'okwibale Mulengera ${ }^{1,2}$, Emmanuel Manzungu $^{3} \&$ Jean Marie Kileshye Onema ${ }^{4}$ \\ ${ }^{1}$ Department of Civil Engineering, University of Zimbabwe, Harare, Zimbabwe \\ ${ }^{2}$ Section des Sciences Exactes, Institut Supérieur Pédagogique de Walungu, Democratic Republic of the Congo \\ ${ }^{3}$ Department of Soil Science and Agricultural Engineering, University of Zimbabwe, Harare, Zimbabwe \\ ${ }^{4}$ WaterNet, Harare, Zimbabwe \\ Correspondence: Emmanuel Manzungu, Department of Soil Science and Agricultural Engineering, University of \\ Zimbabwe, Harare, Zimbabwe. E-mail: manzungu@mweb.co.zw
}

Received: April 27, 2012 Accepted: June 29, 2012 Online Published: August 15, 2012

doi:10.5539/enrr.v2n3p25

URL: http://dx.doi.org/10.5539/enrr.v2n3p25

\begin{abstract}
Semi-arid conditions that prevail in the Limpopo basin in general and Zimbabwe in particular emphasise the importance of water storage. In this respect small reservoirs play a critical role in sustaining rural livelihoods. However, the management of small reservoirs in Zimbabwe is negatively affected by missing or poorly coordinated information relating to such key attributes as location, capacity, and environmental condition. A study was undertaken to identify and characterise small reservoirs in the Limpopo river basin in Zimbabwe. The objective of the study was to identify small reservoirs and characterise them in terms of capacity, and chlorophyll-a and turbidity indices, as proxies for measuring environmental degradation of catchments in which these are located. The study was carried out in Gwanda district that is located in South West Zimbabwe. Identification was done by processing Landsat TM 4-5 images of February-March and April-May 2009, using Geographical Information Systems. Time and cost considerations were the main factors in the selection of the technology and the images that were used. Field inspections were used to validate selected parameters from February to April 2011. A total of 256 small reservoirs, with an estimated total capacity of 17 million $\mathrm{m}^{3}$, were identified. The capacities of reservoirs were found to vary widely from around $4,000 \mathrm{~m}^{3}$ to over $650,000 \mathrm{~m}^{3}$. About half $(46 \%)$ of the small reservoirs were found to be dry by May, just two months after the end of the wet season. Seven reservoirs, which represented $2 \%$ of the total number and $3 \%$ of the total capacity of reservoirs, were characterised as highly turbid. Twenty-three reservoirs, representing $9 \%$ of the total number and $3 \%$ of the total capacity of reservoirs, showed signs of environmental degradation in the catchments. The smallest reservoirs were found to be most vulnerable to environmental degradation. The study concluded that Information and Communication Technologies (ICTs) can successfully be used to identify and characterise small reservoirs in the data-poor Limpopo basin in Zimbabwe, and can be used by decentralised water institutions and River Basin Organisations (RBOs) to better manage available water resources for the benefit of rural communities found therein.
\end{abstract}

Keywords: small reservoirs, rural livelihoods, remote sensing, ICTs, environmental condition, Limpopo

\section{Introduction}

Small reservoirs are important sources of multiple water uses (such as domestic, livestock watering, smallholder irrigation, fishing, dip tanks, and brick making) for rural livelihoods in the Limpopo river basin in general and in Zimbabwe in particular (Manzungu et al., 2009; Senzanje et al., 2008), because of the semi-arid conditions that prevail in the area (Zimbabwe, 1983). In Zimbabwe small reservoirs refer to a storage capacity of less than one million cubic meters and less than eight meters of dam wall (Kabell, 1986). However, the contribution of small reservoirs to rural livelihoods in Zimbabwe is threatened by poor management. This is a consequence of missing or poorly coordinated information (Senzanje \& Chimbari, 2002) on such key attributes as location, capacity, and environmental condition of the reservoirs. Such information is critical for allocating water between competing water uses as well as protection of water resources. 
In Zimbabwe a number of institutions are directly or indirectly involved in the management of small reservoirs. The Zimbabwe National Water Authority (ZINWA), a quasi-government agency, has overall oversight of water management in the country including building and managing dams. For example, by law, ZINWA should be informed before any large dam is constructed (Zimbabwe, 1998). However, ZINWA's mandate does not extend to small dams. All the same ZINWA must be informed when a small reservoir is established. Significantly this is only after its completion (Zimbabwe, 1998). As a consequence ZINWA does not hold a comprehensive database on small reservoirs. Sometimes the management of small reservoirs is left to the discretion of funders of the reservoirs such as Non Governmental Organisations (NGOs), the state-owned District Development Fund (DDF), and local authorities known as rural district councils (RDCs). As the planning and development authorities, RDCs should ideally coordinate the establishment and management of small reservoirs. However, RDCs lack capacity to document small reservoirs, monitor water use, and ensure their environmental protection. More often than not, RDCs tend to leave management of small reservoirs to local people, who also lack capacity to effectively manage them (Mufute et al., 2008).

In order to improve the management of small reservoirs and, consequently, contribute to sustaining rural livelihoods that are dependent on them it is critical that adequate information about them is captured and stored. Information that is needed to effectively manage reservoirs includes, among other things, location of the reservoirs, estimation of their capacity (De Moustier, 1988; DEC, 1987), nutrient load characterisation and quantification (Koelmans \& Lijklema, 1996; Muvundja et al., 2009), as well as assessing environmental impacts (DEC, 1987; Naiman \& Dudgeon, 2009). This can be quite an expensive process if traditional methods are used. However, recent developments in Information and Communication Technologies (ICTs) provide an opportunity to undertake the same task at a fraction of the cost (Hayes \& Rajao, 2011; Jansky \& Uitto, 2005; Singh \& Singh, 2004; Wainwright \& Waring, 2004). ICT refers to the practical application of knowledge involving the development, maintenance, and use of computer systems and electronics in order to process and exchange messages through a common system of symbols (Encyclopaedia Britannica, 2010). Some examples of ICTs are mobile phone telecommunications, radio, television, internet, databases, remote sensing, and geographic information systems (CTA, 2011; Jansky \& Uitto, 2005).

In water resource management ICT has been used to analyse rainfall (Kileshye \& Taigbenu, 2009), locate and estimate capacity of reservoirs (Gupta \& Banerji, 1985; Rakhmatullaev, 2010; Sawunyama et al., 2006) and assess groundwater potential (Moyce et al., 2006). Other applications included characterising water quality (Nas et al., 2010), assessing land use impacts on soil erosion (Shinde et al., 2010), producing geologic and soil maps, and conducting natural disaster and environmental assessments (Lillesand et al., 2004). In Zimbabwe ICTs have been used to collect and process information on small reservoirs in the Limpopo basin. Sawunyama et al. (2006) estimated the capacities of small reservoirs in Insiza district in South West Zimbabwe using remote sensing data and Geographic Information Systems (GIS). However, the study did not go as far as assessing critical management factors such as estimating the change of volume of a reservoir from a wet to a dry period, and assessing environmental conditions of the reservoirs such as assessing the quality of water.

In water quality assessment the first four of the seven bands that constitute Landsat TM 4-5 scenes have been effectively used because of their spectral resolutions that cover a large portion of wavelength between 400 and 850 nm (Hadjimitsis \& Clayton, 2011; Usali \& Ismail, 2010). In this paper, turbidity and chlorophyll-a were chosen forphysico-chemical characterisation of small reservoirs. These two parameters have optical properties that make them measurable by remote sensing, and can accurately indicate the environmental status of the reservoirs (Moore, 1980). Turbidity is the measure of the light scattering in water due to suspended matter (Rasmussen et al., 2009). Chlorophyll-a is the substance responsible for the pigment of algal plants, which gives a good indication of algal biomass in water (Duan et al., 2007). High turbidity of a reservoir is generally caused by inflows that are heavily loaded by suspended matter (Valentin et al., 2008). Inflows that are heavily loaded by nutrients induce excessive algal growth and can cause proliferation of floating vegetation (Monaghan et al., 2009; Muvundja et al., 2009).

This study sought to use freely available Landsat TM 4-5 images in order to identify and characterise small reservoirs in terms of their capacity, turbidity and chlorophyll-a in Limpopo river basin in Zimbabwe. It used Gwanda district as a case study.

\section{Study Area}

The study was undertaken in Gwanda administrative district that is located in Matebeleland South province (Figure 1). 


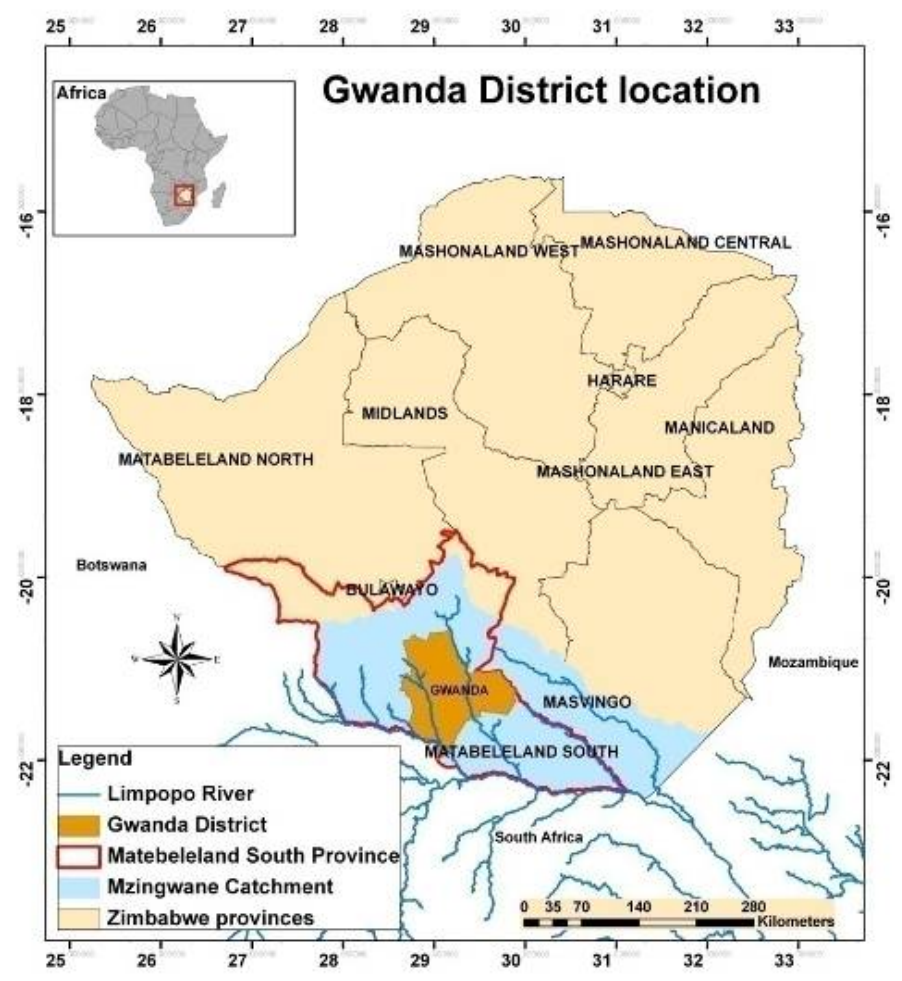

Figure 1. Location map of Gwanda district

The district covers approximately $11000 \mathrm{~km}^{2}$ and is drained by two main rivers, namely the Tuli in the West and Mzingwane in the East. Altitude ranges from around $560 \mathrm{~m}$ in the Southern part to greater than $1300 \mathrm{~m}$ in the Northern part. The district falls in three subcatchments (Shashe, Upper and Lower Mzingwane) in the hydrological zone B, which is one of the six hydrological zones into which Zimbabwe is divided. The zone is characterised by the lowest mean annual runoff (M.A.R ) of $19 \mathrm{~mm}$, and has the highest coefficient of variation $(130 \%)$ in the whole country (Mtisi \& Nicol, 2003; Mupangwa et al., 2008; Zimbabwe, 1983). Lower Mzingwane has the lowest M.A.R of $4 \mathrm{~mm}$ and the highest coefficient of Variation (C.V) of $160 \%$ (Zimbabwe, 1983). Consequently, the streams are generally ephemeral, which underlines the importance of water storage in the area. The rainy season ranges from November to March while the dry season starts from May to September. The soils in the district, which belong to the classes of leptosols, luvisols, lixisols, acrisols, and arenosols (FAO \& UNESCO, 2006), are not suitable for agriculture unless fertilisers are applied (IUSS Working Group WRB, 2006).

Due to the erratic rainfall, rainfed crop production is difficult. Livestock farming is an important livelihood strategy. The main source of income is cattle and small stock production, although this is undertaken at subsistence level (PlanAfric, 2000). The human population in the district is estimated to be 133,167 in 2002 (CSO, 2002) and 150,000 in 2010 (UN, 2010). The general population in the communal areas is relatively poor (PlanAfric, 2000), and is characterised by an illiteracy level of around $18 \%$ and a Human Development Index (HDI) of 0.60 (FAO, 2011). This is worsened by a high rate of unemployment (UN, 2010).

\section{Material and Methods}

\subsection{Overview of Methodological Approach}

The methodological approach used in the study, as illustrated in Figure 2, consisted of four main steps:

1) Supervised classification of land cover using satellite images in order to extract areas of water bodies;

2) Identification and characterization of small reservoirs by determining turbidity and chlorophyll-a indices from satellite images;

3) Estimation of small reservoirs capacity from remotely sensed acquired information for wet and dry periods; and

4) Ground validation of obtained results. 
These steps were carried out from January 2011 to April 2011. The Geographical Information Systems software ILWIS 3.31 was used. Mathematical and statistical computations were done using Excel and SPSS.

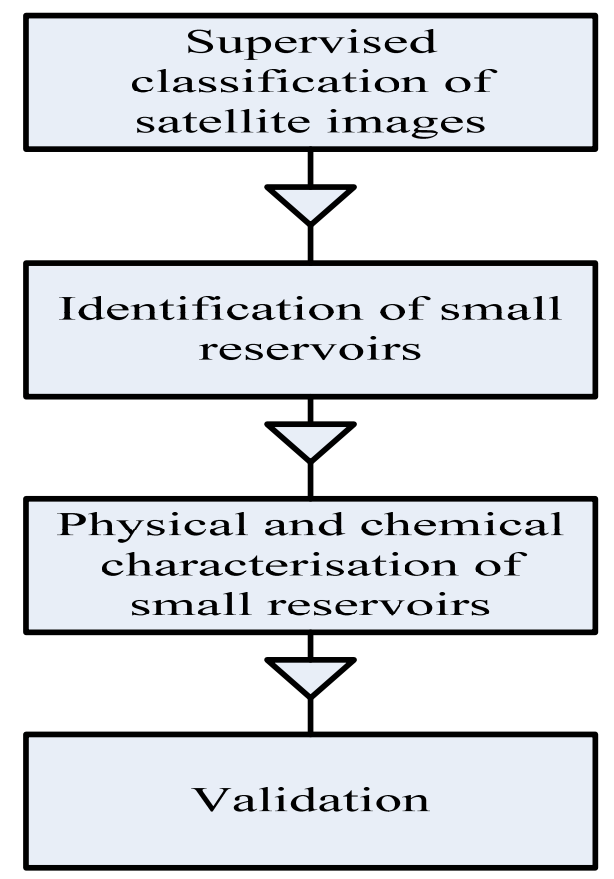

Figure 2. Methodological approach

\subsection{Classification of Land Cover}

To classify the land cover characteristics of the district, satellite images from Landsat TM 4-5 collection were chosen. The following reasons justified the choice of the particular images:

a. The sensor has seven bands that cover a spectral resolution ranging from the visible to the infrared region (that is good for characterizing most of Earth surface materials and water in particular);

b. The images are freely available and generally free of stripes;

c. The spatial resolution of $30 \mathrm{~m}$ that characterizes the bands $1,2,3,4,5$ used in this study ${ }_{2}$ is good enough to identify small reservoirs; and

d. The sensor records images at a radiometric resolution of 8 bits, which provides enough detail of information by discriminating 256 levels of reflectance intensity in a particular wavelength. This was important for both the classification of land cover in general and the physical and chemical characterization of small reservoirs in particular.

The satellite images were downloaded from the USGS website (http://glovis.usgs.gov) using the geographic coordinates of the boundaries of the district. Selecting appropriate images of the Landsat TM 4-5 collection was based on the following considerations:

1) Images that covered the geographic location of Gwanda district and were preferably cloud-free;

2) Latest images in order to identify all small reservoirs, including the most recently developed ; and

3) Two sets of images of the same year representing the wet and dry season so as to be able to estimate the capacity of the reservoirs in the two seasons.

Four scenes of Landsat TM 4-5 images were necessary to cover the whole district per season. Images of February-March 2009 were downloaded, which represented the end of the rainy season. There was, however, a challenge in finding recent images of around September that could be used to better estimate dry season capacity. The latest available images were around May 2009. All the images had low sun elevation angles, ranging from 36.7 to $55.1^{\circ}$. Low sun elevation is known to generate shadows in the presence of abrupt topography, which affects the classification of land cover types of low reflectance such as clear or deep water (Srestha \& Zinck, 2001). These shadows were filtered from the classification using the first critical index of the identified small 
reservoirs, as will be later explained.

Geometric and radiometric pre-processing of the images was done in order to fix satellite distortions, variation in solar illumination, and atmospheric effects on acquired images (Ouaidrari \& Vermote, 1999; Verbyla \& Boles, 2000). Geometric correction was carried out using an affine transformation on the basis of two topographic maps of 1:50,000 scale that cover the district. The nearest neighbour method was applied for resampling. Radiometric calibration was done based on standard procedure, as described by Chander and Markham (2003). Satellite images tiles were merged per spectral band and per period in order to obtain individual bands that cover the entirety of the district as per defined period.

A supervised classification was then run based on pseudo-natural colour composite (bands 5, 4, 3 for channels Red, Green, Blue) using the minimum distance to mean algorithm. A 2\% histogram equalisation was applied for contrast enhancement. Six classes of land cover were sampled based on their specific spectral reflectances that could be distinctly separated on the pseudo-natural colour composite. These were clear or deep water and shadows, shallow or turbid water, forests and shrubs, healthy vegetation, white soil/sand, and brown soil/clay.

\subsection{Identification and Characterisation of Small Reservoirs}

\subsubsection{Identification}

From the six classes of the classified images, the two classes of water (clear or deep water and shallow or turbid water) were merged into one class of "water bodies". The capacity-area relationship developed by Sawunyama et al. (2006), for which the $\mathrm{R}^{2}$ was $95 \%$, was used to determine the size limit in terms of surface area between small and larger reservoirs as defined (in volume terms) in Zimbabwe (Kabell, 1986; Zimbabwe, 1998). The reservoirs polygons were formed based on the contiguity of pixels using an automated 8-pixel connection method (that connects in horizontal, vertical, and diagonal pixels) and assigning such connected pixels a unique identifier. To that unique identifier was associated the location coordinates of the point at the center of the polygon. The surface areas were calculated based on the number of pixels that formed each polygon, taking into account that each pixel constitutes a square of $30 \mathrm{~m}$ wide. A threshold of 2 pixels was set to classify negligible water bodies. To remove larger residual water bodies in main rivers, namely Tuli and Mzingwane rivers, a masking map was created.

\subsubsection{Characterisation of Turbidity and Chlorophyll-a}

Reflectance data of Landsat TM 4-5 images have been used to develop algorithms that directly output the parameter under study from the input of reflectance in one or more satellite bands (Bustamante et al., 2009; Raharimahefa \& Kusky, 2010). However, the development of such models depends on the availability of in situ data to correlate with reflectance on the time of satellite overpass (Hadjimitsis et al., 2006; Nas et al., 2010). Again, the models are very diverse and specific to the reservoirs studied, which makes them not replicable elsewhere. It was concluded that this approach was not applicable in the case of small reservoirs in Gwanda district because of challenges highlighted above, which relate to data availability as well as time and costs considerations.

Although they differ in the quantification of the physico-chemical property studied, these divergent models have in common the reflectance bands, bands ratios, or bands combinations that strongly correlate with in situ measurements (Hadjimitsis \& Clayton, 2011). Thus well selected bands can be used to effectively characterise the physico-chemical property in terms of a unitless index. Bands ratios are generally preferred because of the ability to discriminate atmospheric effects, and shadows due to variation of topography and sun elevation (Lawrence \& Ripple, 1998; Nas et al., 2010; Raharimahefa \& Kusky, 2010). In this paper, bands ratios were therefore chosen as indices of turbidity and chlorophyll-a.

Best prediction of turbidity is performed with algorithms based on single bands 3 or 2 of Landsat TM 4-5 (Brezonik et al., 2005; Bustamante et al., 2009; Hadjimitsis et al., 2006; Nas et al., 2010), while band 1 also characterises turbidity by providing the best penetration in water (Raharimahefa \& Kusky, 2010). Some studies have demonstrated that the ratios (band 3)/(band 1) and (band 2)/(band 1) best correlate with in situ measurements of turbidity (Nas et al., 2010; Raharimahefa \& Kusky, 2010). The turbidity index used in this study is thus the sum of the two ratios in a way that considers the spectral ranges where turbidity best correlates:

$$
\text { Landsat TM 4-5 Turbidity Index }=(\text { Band } 3+\text { Band } 2) /(\text { Band } 1)
$$

To characterise chlorophyll-a, Duan et al. (2007) showed that the reflectance of this substance positively correlates in bands 2 and 4 and has a remarkable pic of absorption in band 3 of Landsat TM 4-5 (Figure 3).

In this order, the simple ratio of vegetation index (Band 4)/(Band 3) and the ratio (Band 2)/(Band 3) are best indicators of chlorophyll-a reflectance (Duan et al., 2007; Raharimahefa \& Kusky, 2010). 
The chlorophyll-a index used in this study is thus the sum of the two ratios in a way that considers the spectral ranges where chlorophyll-a concentration best correlates with spectral reflectance:

$$
\text { Landsat TM chlorophyll-a index }=(\text { Band } 2+\text { Band } 4) /(\text { Band } 3)
$$

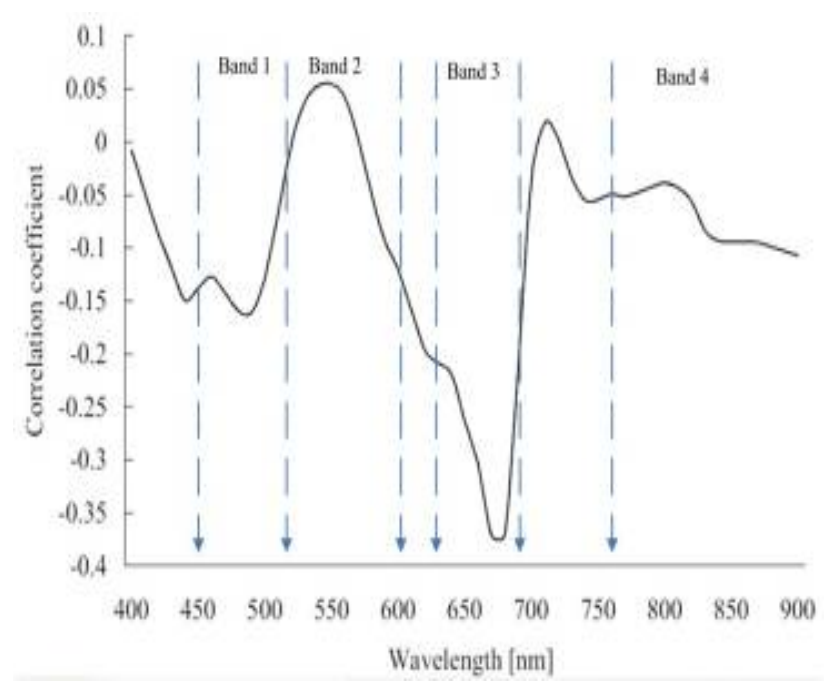

Figure 3. Correlation between chlorophyll-a concentration and reflectance in Landsat TM bands

To characterise the critical turbidity and chlorophyll-a of small reservoirs, it is important to consider the magnitude of these parameters compared to specified thresholds. To determine these thresholds (or critical indices) there are three aspects that need consideration. Firstly, remotely sensed turbidity from satellite is generally affected by the bottom soil reflectance of shallow reservoirs (Bustamante et al., 2009; Tolk et al., 2000). Secondly, ratio-based vegetation indices effectively discriminate shadows from clear water (Lawrence \& Ripple, 1998). Thirdly, Irigoien and Castel (1997) found that excessive turbidity hinders chlorophyll-a concentration despite large inputs of nutrients. In the same vein, Scheffer et al. (2001) found that turbidity becomes critical when it continues increasing without increase in vegetation and, conversely, vegetation growth becomes critical when it continues increasing without turbidity increase.

Therefore, to characterise the environmental degradation of small reservoirs in the district, critical turbidity and chlorophyll-a indices were determined by the points of change of relationships between equations (1) and (2). As a prerequisite, the coefficients of determination $\left(\mathrm{R}^{2}\right)$ of these relationships were considered not to be affected by collinearity between the two equations. This is because the ratios $\mathrm{B} 3 / \mathrm{B} 1$ and $\mathrm{B} 2 / \mathrm{B} 1$, which were used for turbidity index (Equation 1), do not correlate ( $\mathrm{R}^{2}$ of less than 0.05 ) with chlorophyll-a concentration (Duan et al., 2007).

The highest and lowest values of the critical indices were determined on the basis of the absolute error that characterised the critical indices. These values represented the limits of the interval in which the change of relationship between turbidity and chlorophyll-a was occuring.

Considering that vegetation-based ratio indices discriminate shadows (Lawrence \& Ripple, 1998), two critical indices of chlorophyll-a were determined. The first was used to eliminate shadows from the class of 'clear or deep water', using the criteria that they were characterised by an index greater than the lowest value of the first critical chlorophyll-a index. In this order, 'true reservoirs' remained. The second critical index was used to categorise 'true reservoirs' that are loaded with excessive vegetation and those that are not.

Four subclasses were determined considering the categorisation of small reservoirs based on the critical turbidity and chlorophyll-a indices, namely:

1) "Highly turbid" reservoirs were characterised by turbidity indices greater than the highest critical turbidity index;

2) "Moderately turbid" reservoirs were characterised by turbidity indices between the highest and lowest critical turbidity indices;

3) "Clear water and no floating vegetation" reservoirs were characterised by turbidity indices less than the lowest 
critical turbidity index, and chlorophyll-a indices less than the lowest value of the second critical chlorophyll-a index; and

4) "Clear water but excessive floating vegetation" reservoirs were characterised by chlorophyll-a indices between the first and the lowest value of the second critical chlorophyll-a indices.

As far as decision-making is concerned, only the first and last types of reservoir require immediate attention as this impact on sustainability. Reservoirs of type (1) and (4) indicate poor erosion control and excessive nutrients loads, while type (2) reservoirs represent an ordinary status that includes the bottom soil reflectance of shallow ones. Type (3) reservoirs represent the best status of neither excessive turbidity nor excessive chlorophyll-a.

\subsubsection{Capacity Estimation of Reservoirs}

In order to use remote sensing for measuring a physical or chemical water parameter, it is important that the satellite images represent similar conditions of time and place of data collection or to use a model that was validated with field data (Bustamante et al., 2009; Hadjimitsis \& Clayton, 2011). This consideration was confirmed by the diversity of models to estimate the capacity of small reservoirs, which were discussed to be sensitive to climatic conditions in the period of their development (Sawunyama et al., 2006).

In general, a small reservoir can be represented like a pyramid (Figure 4).
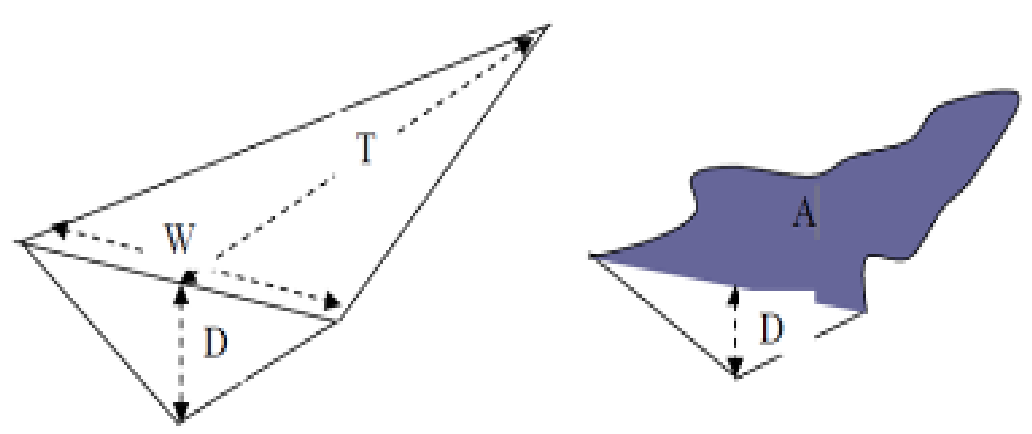

Figure 4. Pyramidal model for reservoir's capacity estimation (Sawunyama, 2005)

In this case, the capacity is estimated using the formula of the volume of a pyramid (3):

$$
\mathrm{C}_{1}=(\mathrm{A} * \mathrm{D}) / 3
$$

where $\mathrm{D}$ is the depth of water at the deepest point close to the dam wall, and $\mathrm{A}$ is the surface area. Although the surface area is easy to determine by remote sensing, field data is necessary to determine D for each small reservoir. This is time and resources intensive.

A relationship to directly estimate the capacity of a small reservoir from its surface area (4) was developed by Sawunyama et al. (2006) using field data in Insiza district, which also falls in the general study area:

$$
\mathrm{C} 2=0.023 * \mathrm{~A} 1.33(\mathrm{R} 2=0.95)
$$

This relationship was found very useful to estimate capacity because it only depends on the surface area of the reservoir that can be found by remote sensing. Indeed, the calculation of coefficients of variation (5) of the field data generated during the development of the relationship (Table 1) shows high variation of volume capacity ( 0.98 , which is a good sign of a well diversified sample) and surface area (0.72), in opposition to low variation $(0.22)$ for the pyramid model depth (6).

$$
\begin{gathered}
\mathrm{C} . \mathrm{V}=(\text { Standard deviation }) /(\text { Average }) \\
\mathrm{D}=3 * \mathrm{Vf} / \mathrm{Af}
\end{gathered}
$$

where $V_{f}$ and $A_{f}$ represent respectively the volume and the surface area determined from field measurements.

This explains why capacity could be expressed as a direct function of the area (4) while the variation of the depth $\mathrm{D}$ could be considered negligible. To put it differently, the depth $\mathrm{D}$ of small reservoirs can be considered as constant despite the significant variation in volume and surface area. In this regard, an average depth D of small reservoirs could be effectively used to estimate capacities. To validate this point, the application in (3) of the average depth of small reservoirs used by Sawunyama et al. (2006), which is 1.97 , was used which gives a relative volume difference (7) of only $10 \%$ with the figures obtained with (4). This proves that the pyramidal 
model is effectively applicable if the average depth of small reservoirs is known.

$$
\mathrm{RVD}=100 *[\Sigma(\mathrm{C} 1-\mathrm{C} 2) / \Sigma \mathrm{C} 2]
$$

However, in order to apply the relationship (4) to other conditions of time and place, the authors pointed out that further research was necessary especially in heterogenous conditions (Sawunyama et al., 2006). Suchheterogeneous conditions exist in the Mzingwane catchment, the study area. The heterogeneity is illustrated by the catchment sub-zones that are characterised by significantly different mean annual runoff (M.A.R), ranging from 1 to 80, and coefficients of variation (C.V) of above 100 (Zimbabwe, 1983).

Consequently, this study used the average depth of a diversified sample of small reservoirs in Gwanda district. The validation process, which is further discussed below, enabled a choice between equations (3) and (4). The chosen equation was applied to both wet and dry season images in order to determine the capacity of all the small reservoirs in both seasons. A trend was deduced between wet and dry period capacities in order to establish the minimum size that could not go beyond the month of May, which marks the beginning of the dry season.

Table 1. Data used for establishing the capacity-area relationship in Insiza (Sawunyama et al., 2006)

\begin{tabular}{|c|c|c|c|c|c|c|}
\hline Name of reservoir & $\begin{array}{l}\text { Vf, volume } \\
\text { field }\end{array}$ & $\begin{array}{l}\text { Af, area } \\
\text { field }\end{array}$ & $\mathrm{D}=3 * \mathrm{Vf} / \mathrm{Af}$ & $\begin{array}{c}\mathrm{C}_{1} \text { (average } \\
\mathrm{D})\end{array}$ & $\mathrm{C}_{2}$ & $\mathrm{C}_{1}-\mathrm{C}_{2}$ \\
\hline Sibasa & 8114 & 15090 & 1.61 & 9926 & 10722 & -796 \\
\hline Dehwa & 17146 & 26516 & 1.94 & 17442 & 16037 & 1405 \\
\hline Avoca & 41031 & 51171 & 2.41 & 33659 & 42155 & -8496 \\
\hline Manzamhlope & 15258 & 24284 & 1.88 & 15973 & 13588 & 2385 \\
\hline Vocola & 11246 & 19297 & 1.75 & 12693 & 9132 & 3561 \\
\hline Mashoko & 87504 & 90543 & 2.90 & 59557 & 85306 & -25749 \\
\hline Tekwani & 3244 & 7562 & 1.29 & 4974 & 2863 & 2111 \\
\hline Bova & 14160 & 22955 & 1.85 & 15099 & 11478 & 3621 \\
\hline Sifinini & 11582 & 19730 & 1.76 & 12978 & 11469 & 1509 \\
\hline Ndlegu & 43405 & 53387 & 2.44 & 35117 & 45940 & -10823 \\
\hline Masuto & 12470 & 20859 & 1.79 & 13721 & 11741 & 1980 \\
\hline \multirow[t]{2}{*}{ Mbondo } & 21775 & 31747 & 2.06 & 20882 & 20564 & 318 \\
\hline & & & & total & 280995 & -28974 \\
\hline average & 23911 & 31928 & 1.97 & & & \\
\hline Standard deviation & 23466 & 22849 & 0.43 & & RVD & -10 \\
\hline C.V & 0.98 & 0.72 & 0.22 & & & \\
\hline
\end{tabular}

\subsection{Validation}

Field work was carried out from February to April 2011 to validate the land cover classification by using the coordinates of the water bodies. Features identified as shadows due to abrupt topography were validated using higher resolution images of Google Earth. They were then eliminated from the captured polygons of clear or deep waters. A random sampling of representative coordinates of 11 areas identified as shadows was used for the validation.

Turbidity measurements were carried out on 10 small reservoirs sampled in all the classes of turbidity. The measurements were correlated to the respective indices. Small reservoirs in the three categories based on chlorophyll-a index (excessive floating vegetation, sparse vegetation, and no vegetation) were visited. Correlations were carried out between the respective indices and the observed presence of floating vegetation on the ground. The presence and intensity of floating vegetation observed on the field was coded as follows: 1 (no vegetation), 2 (sparse floating vegetation) and 3 (excessive floating vegetation). This was performed for 25 small reservoirs.

To validate the applicability of the equations (3) or (4) to the small reservoirs in Gwanda district, the procedure illustrated in Figure 5 was used. Data presented by Sawunyama et al. (2006) was used for small reservoirs in 
Insiza district (Table 1). Field work was carried out on 10 small reservoirs in Gwanda district to measure the pyramidal depth. The reservoirs were sampled on the basis of a high coefficient of variation of surface areas. To validate equation 4, a reliability analysis of scale was performed on surface areas and pyramidal depth of small reservoirs in Insiza and Gwanda districts. This step helped to determine if equation 4 could be applied on small reservoirs that are comparable for both districts in terms of surface areas and pyramidal depth. Equation 4 developed in Insiza district could be successfully used if those conditions were met. On the contrary, equation (3) could be used with an average pyramidal depth on the condition that the coefficient of variation (C.V) of the depth was less than the one for the surface area. This validated the point that the surface area is the most determinant parameter of the volume. If all these conditions are not met, none of the equations can be used to successfully estimate capacities of all small reservoirs.

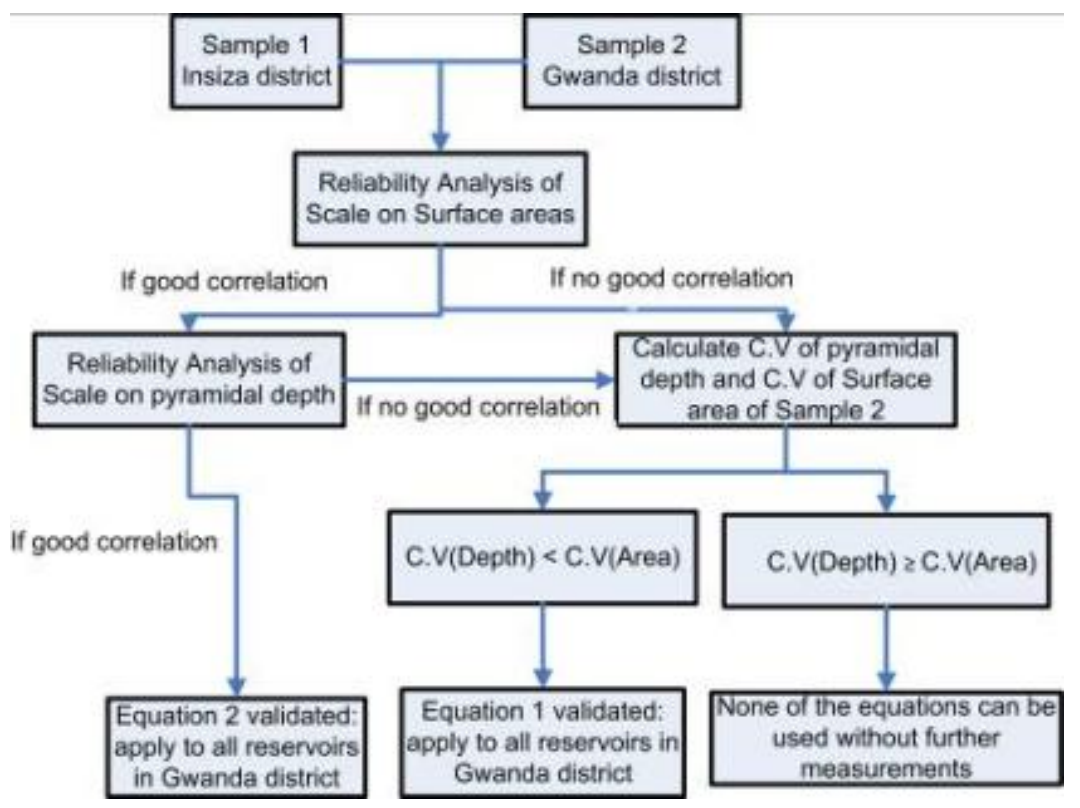

Figure 5. Validation and choice of capacity estimation

\section{Results}

\subsection{Land Cover Classification}

With an overall accuracy of $93.44 \%$ for the first set of images, and an overall accuracy of $91.58 \%$ for the second, the confusion matrices suggested a good confidence level in the obtained classification. The classification of satellite images of the six classes identified is presented in Table 2 for both wet and dry period.

Table 2. Classification of land cover for wet and dry periods

\begin{tabular}{|c|c|c|c|c|c|}
\hline & \multirow[b]{2}{*}{ Feature Class } & \multicolumn{2}{|c|}{ First set of images } & \multicolumn{2}{|c|}{ Second set of images } \\
\hline & & $\begin{array}{c}\text { Surface area } \\
\text { percentage }\end{array}$ & $\begin{array}{c}\text { Grouped } \\
\text { percentage }\end{array}$ & $\begin{array}{c}\text { Surface area } \\
\text { percentage }\end{array}$ & $\begin{array}{c}\text { grouped } \\
\text { percentage }\end{array}$ \\
\hline 1 & forests and shrubs & 77.86 & 79.55 & 31.68 & 31.70 \\
\hline 2 & healthy vegetation & 1.69 & vegetation & 0.02 & vegetation \\
\hline 3 & white soil/sand & 18.77 & & 6.19 & \\
\hline 4 & brown soil/clay & 1.17 & 19.94 bare so1l & 61.58 & $6 \% .77$ bare so1l \\
\hline 5 & clear or deep water and shadows & 0.31 & & 0.45 & \\
\hline 6 & shallow or turbid water & 0.12 & & 0.06 & \\
\hline & undefined areas & 0.08 & 0.08 undefined & 0.02 & 0.02 undefined \\
\hline & total & 100 & 100 & 100 & 100 \\
\hline
\end{tabular}


Table 2 shows that there was a change in major land cover types between the respective periods of the two sets of images. This was characterised by a reduction in vegetation from around $80 \%$ in February-March to around $32 \%$ in May 2009, and an increase in bare soil from around 20\% in February-March to around 68\% in May 2009 The class of 'clear or deep water' was affected by the bias caused by increased shadows size induced by lower sun elevations in dry season images (Figure 6) than in wet season images (Figure 7).

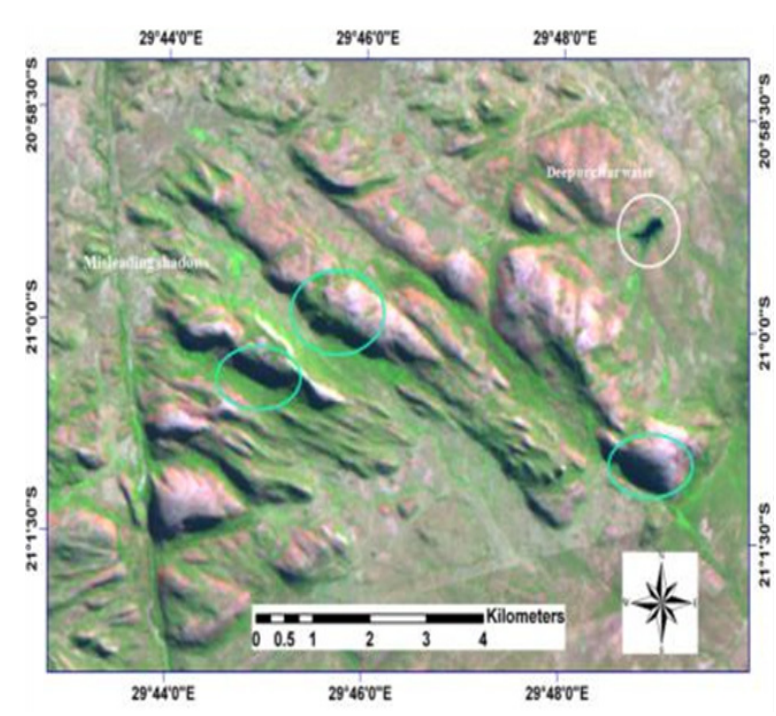

Figure 6. Dry season images in false colour composite (large shadows in green circles)

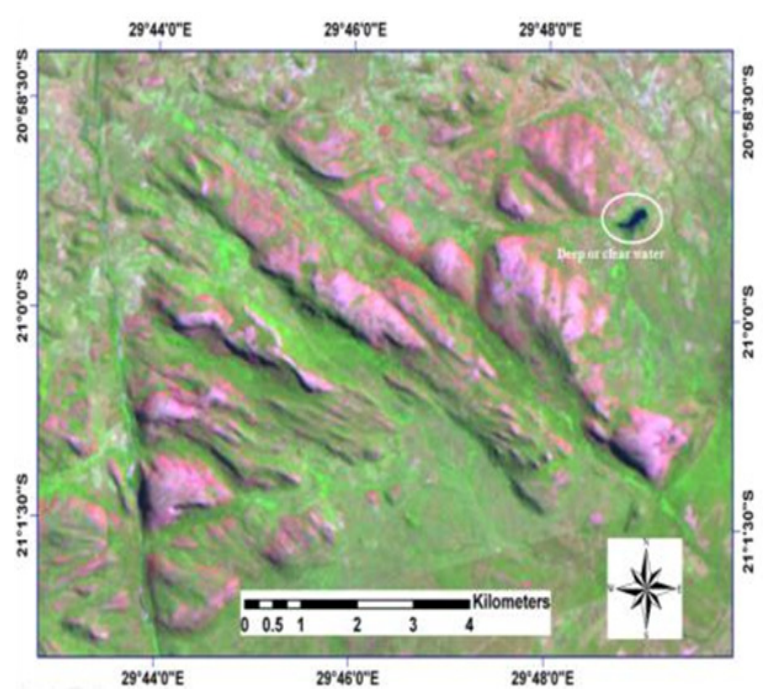

Figure 7. Rainy season images in false colour composite (shadows less observed)

\subsection{Determination of Number of Small Reservoirs and Their Physico-chemical Status}

\subsubsection{Preliminary Number of Small Reservoirs}

Using the classes specified above, the number of identified reservoirs in Gwanda district was obtained and their respective sizes (Table 3).

Table 3. Sizes categories of identified reservoirs in Gwanda district

\begin{tabular}{ccc}
\hline Category of reservoir & Criteria & $\begin{array}{c}\text { Number of reservoirs in } \\
\text { category }\end{array}$ \\
\hline $\begin{array}{c}\text { Medium to large } \\
\text { reservoirs }\end{array}$ & More than 614 pixels & 7 \\
Small reservoirs & More than 2 and at most 614 & 473 \\
pixels & or 2 pixels & 359 \\
Togligible reservoirs & & 839 \\
\hline
\end{tabular}

The 473 identified small reservoirs in Table 3 still contain confusion of "clear or deep water" with shadows due to low sun elevation and topography variation.

\subsubsection{Physico-chemical Status}

Figure 8 shows the relationship between turbidity and chlorophyll-a indices for the 473 small reservoirs. This was used to find the critical turbidity.

The change in relationship between turbidity index and chlorophyll-a index in a second degree trendline equation is shown in Figure 8. Using this equation, the point of change in the trend was determined by calculating the value for which the following derivative was null. In this order: 
$(\mathrm{dy} / \mathrm{dx})=0$,

Thus: $7.848 * 2 * x-20.63=0$

Consequently: $\mathrm{x}=1.31$ was the turbidity index from which the turbidity of the reservoir was considered as critical. Considering the confidence level of $83.6 \%$, the critical turbidity index could be written with its absolute error as $1.31( \pm 0.215)$. In other words, the lower and upper limits of the turbidity index were 1.095 and 1.525 .

From this we can deduce the following:

1) Any small reservoir with a turbidity index greater than or equal to 1.525 is highly turbid. 7 small reservoirs corresponded to this criteria;

2) Any small reservoir with a turbidity index greater than or equal to 1.095 but less than 1.525 can be considered as moderately turbid and a total of 79 reservoirs fell under this criterion; and

3) Any small reservoir with a turbidity index of less than 1.095 can be considered as less turbid or clear water. However, the category of clear water includes shadows, as pointed out earlier, which will be discriminated using critical chlorophyll-a index.

Figure 9 was used to determine the critical chlorophyll-a index.

From the trendline's equation (confidence level of $86.7 \%$ ), the point of change in chlorophyll-a index (more of vegetation than water) is calculated as the point of inflexion of this second order equation, using derivatives:

$(\mathrm{dy} / \mathrm{dx})=0$,

Thus: $0.105 * 2 * x-0.777=0$

Consequently: $\mathrm{x}=3.70$ is the chlorophyll-a index from which the algal biomass concentration increases without increase in turbidity. This represents more biomass than water. Considering the confidence level of $86.7 \%$, the critical chlorophyll-a index can be written with its absolute error as $3.70 \pm 0.493$. In other words, its lower and upper limits are 3.207 and 4.193.

The following observations can be drawn:

1) Any "small reservoir" with a chlorophyll-a index greater than or equal to 3.207 can be considered to be more of vegetation than a water reservoir (a total of 217 polygons picked as "small reservoirs water" that are associated to shadows due to topography and low sun elevation corresponded to this criteria), and

2) Any small reservoir with a chlorophyll-a index lesser than 3.207 is a true water reservoir, and contains more water than vegetation (256 small reservoirs corresponded to this criteria).

Figure 10 shows the second critical chlorophyll-a index for the 256 small reservoirs.

The first derivative of the trendline equation of Figure 10 was used to determine the second critical chlorophyll-a index. This was found to be 2.846 . This means that at $85.4 \%$ confidence level, any small reservoir characterized by a chlorophyll-a index greater or equal to 2.846 is susceptible to develop dense floating vegetation on its surface. Conversely, any small reservoir for which the chlorophyll-a index is less than this threshold, is categorized as a reservoir with no vegetation spreading (233 of the 256 small reservoirs were found in this category).

\subsubsection{Final Number and Physico-chemical Characterisation of Small Reservoirs}

The final identification and physico-chemical characterisation of small reservoirs from above is summarised in the Figure 11. 


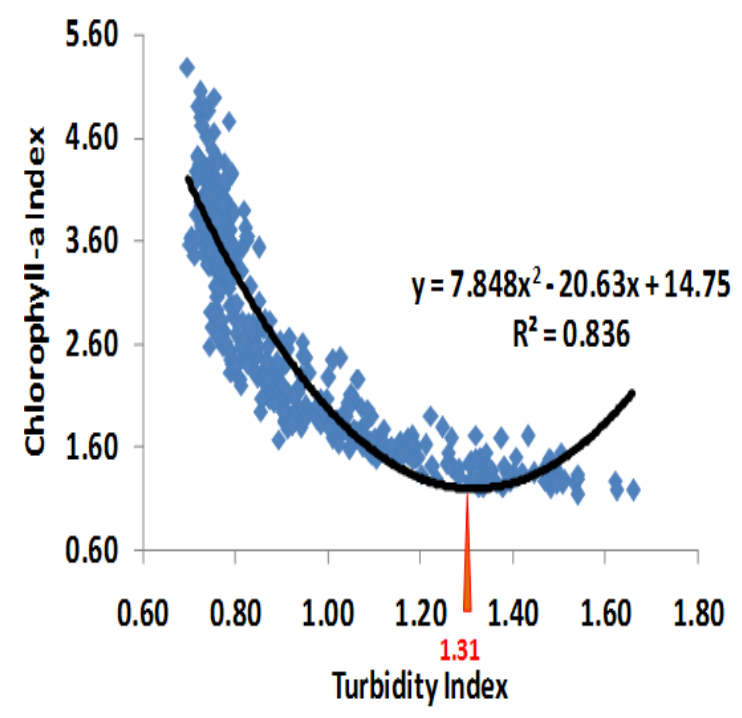

Figure 8 . Determination of the critical turbidity index

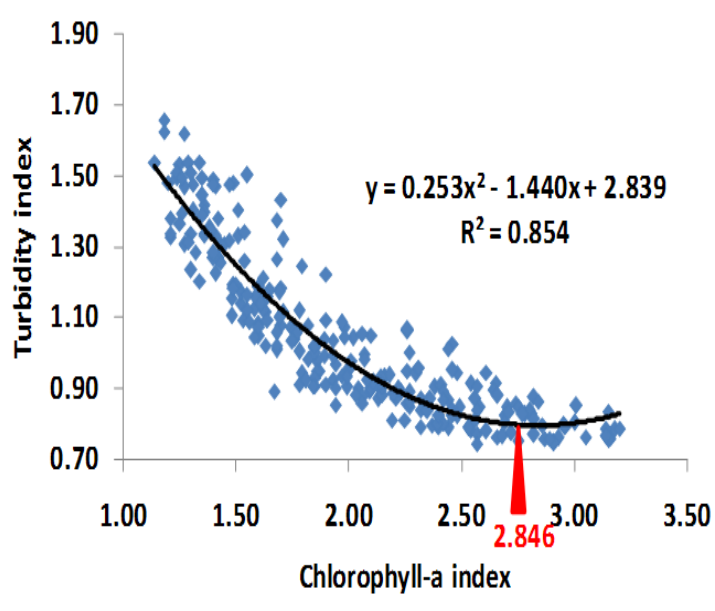

Figure 10. Determination of the second critical chlorophyll-a index

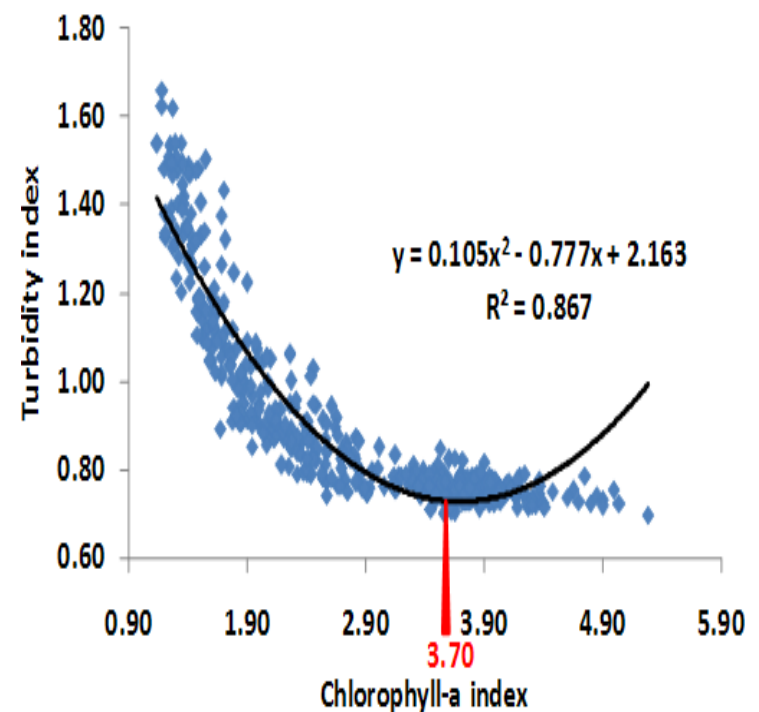

Figure 9. Determination of the first critical Chlorophyll-a index

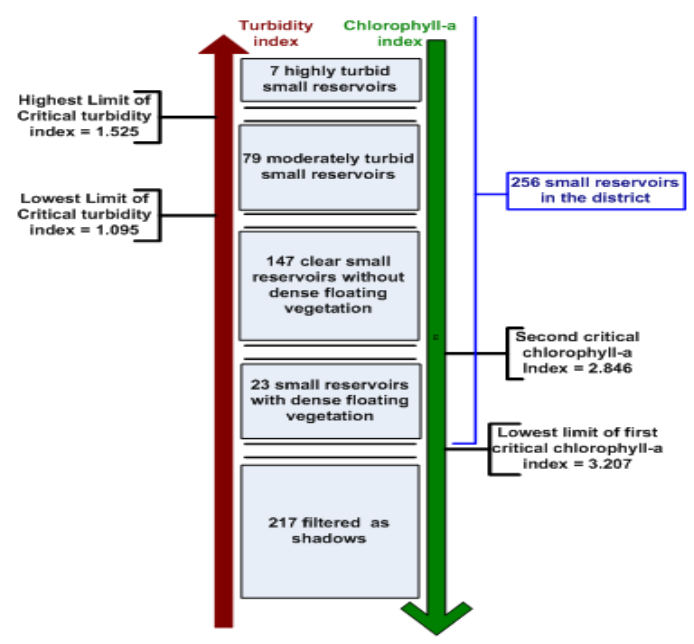

Figure 11. Summary of identification and physico-chemical characterisation

\subsection{Estimation of Capacity}

\subsubsection{Choice and Validation of Model}

The reliability analysis of scale was based on 10 cases between small reservoirs in Gwanda district and the ones used by Sawunyama et al. (2006). The unbiased estimate of reliability was 0.76 for surface areas and -1.22 for the pyramidal depth. In other words, the small reservoirs in the two samples were found comparable with respect to their surface areas only, but not for the pyramidal depth. Therefore, the conditions to apply the capacity-area relationship determined in Insiza district were not met for Gwanda district.

The C.V of the small reservoirs in Gwanda district was found to be 0.85 for surface area and 0.31 for their pyramidal depth (Table 4).

The conditions to use the pyramidal model based on an average depth of small reservoirs were therefore realised. The average depth was found to be $4.25 \mathrm{~m}$. 
Table 4. Depth and surface area of sampled reservoirs in Gwanda district

\begin{tabular}{lll}
\hline reservoir & depth $(\mathrm{m})$ & area $(\mathrm{m} 2)$ \\
\hline Sivume & 2 & 10800 \\
Sophaphu & 3 & 25200 \\
Langaphakathi 2 & 4 & 10800 \\
Dondoriyo & 4 & 17100 \\
Ngonyama & 4 & 37800 \\
Matsenyane & 4 & 67500 \\
Mgodi & 4.5 & 5400 \\
Matambo & 5 & 5400 \\
Langaphakathi 1 & 5 & 45000 \\
Makhanka & 7 & 13500 \\
& & \\
average & 4.25 & 23850 \\
Standard deviation & 1.32 & 20339 \\
C.V & 0.31 & 0.85 \\
\hline
\end{tabular}
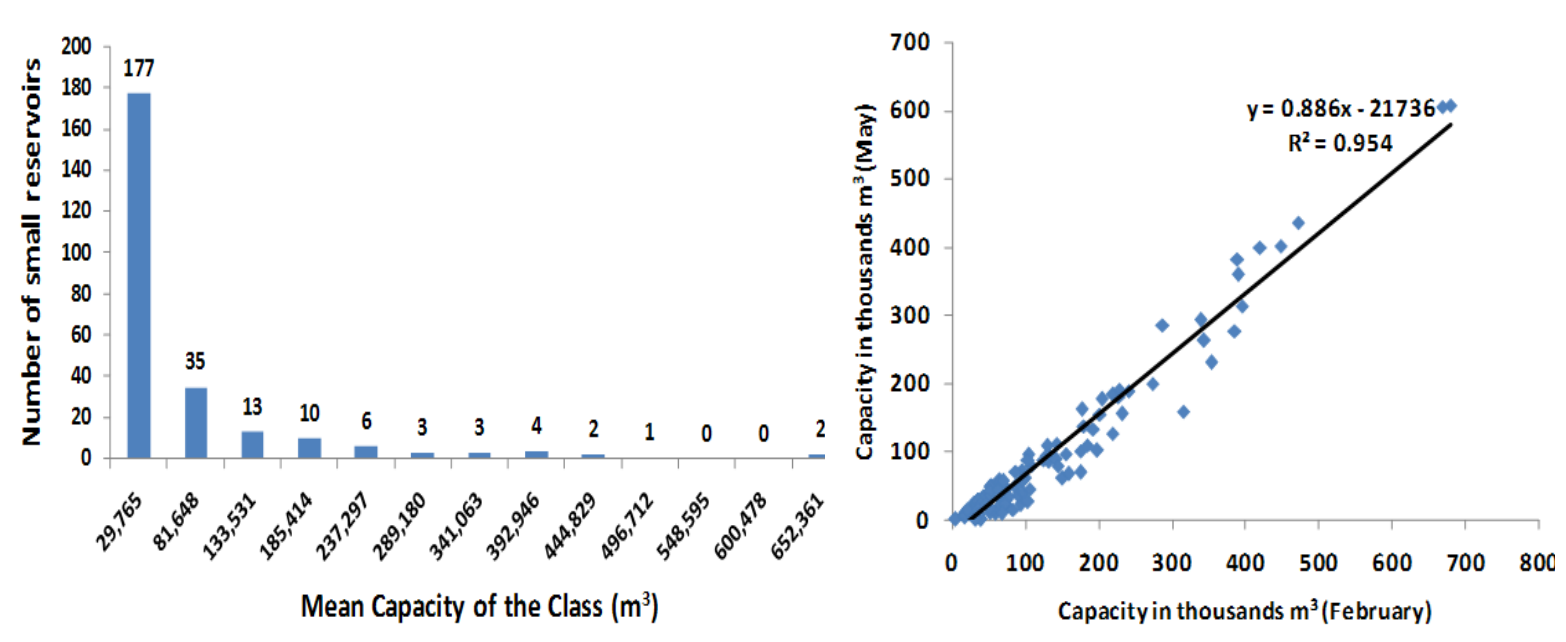

Figure 12. Distribution of mean capacities among small

Figure 13. Drying relationship of small reservoirs reservoirs

\subsubsection{Application of Model}

The total capacity of small reservoirs in the district was then estimated to 17 million $\mathrm{m}^{3}$. The volume capacity that is within the 7 highly turbid reservoirs ( $2 \%$ of the total number) corresponds to approximately $3 \%$ of the total capacity. The 23 small reservoirs, corresponding to $9 \%$ of the total number, are characterised by excessive floating vegetation amount for about $3 \%$ of the total capacity.

The largest estimated capacity value $\left(678,300 \mathrm{~m}^{3}\right)$ is more than 150 times bigger than the smallest $\left(3,824 \mathrm{~m}^{3}\right)$, indicating a wide range of capacities for small reservoirs in the district (Figure 12). This wide range distribution of capacities is very much skewed to right $(+2.97)$, in the same way the median (value which divides the distribution in two equal parts, which is $\left.28,687 \mathrm{~m}^{3}\right)$ is lower than the half of the average value $\left(67,919 \mathrm{~m}^{3}\right)$. Thus most of the small reservoirs (69\% of the 256 small reservoirs) were found to have small capacities of around $30000 \mathrm{~m}^{3}$ (Figure 12). 
Based on this trend, only small reservoirs of a size greater than $24533 \mathrm{~m}^{3}$ were found able to carry water beyond the month of May. Some 119 small reservoirs ( $46 \%$ of the total number of small reservoirs) were identified as likely to fail by May due to the dry season and their very small capacity.

\subsection{Validation}

The field visit to 27 small reservoirs served to validate the classification and identification of small reservoirs at $100 \%$. All the 11 areas' coordinates used in Google Earth were also confirmed to be shadows behind abrupt topography.

Strong linear correlation of 0.79 was found between the turbidity index and the field measurement of turbidity. The measured turbidity varied from around 20 NTU for the clearest reservoirs to above 300 NTU for the highly turbid reservoirs (Figure 14).

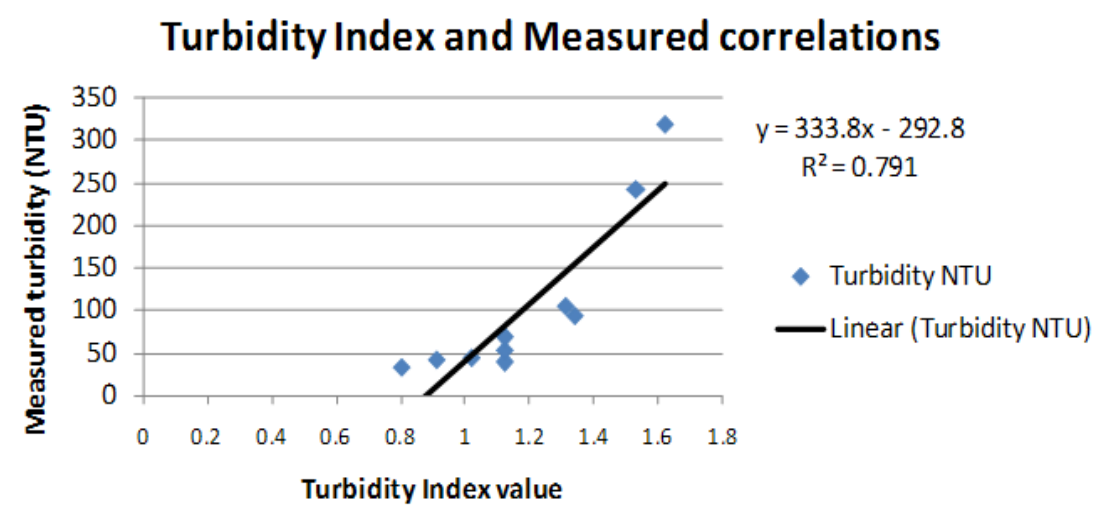

Figure 14. Correlation between measured turbidity and turbidity index

A good linear correlation of 0.68 was found between the encoded presence of vegetation and the respective chlorophyll-a index. This good correlation indicates the effectiveness of the indices used and their ability to be used over time to monitor small reservoirs in particular and water resources in general, using remote sensing data and GIS.

\section{Discussion and Conclusions}

The changes in land cover showed that the first and second sets of images can be considered to be representing a wetter and a drier period respectively. It was also observed that the sun elevation level went down to about $12^{\circ}$ in the drier season images. This was the reason why wide shadowed areas in front of abrupt topography were either generated or increased (Figures 6 and 7). As a consequence, a bias in the class of 'clear or deep water' was induced -it was the class with the lowest reflectance in all bands. Similar issues have been pointed out in studies that dealt with the classification of land cover in mountainous area (Srestha \& Zinck, 2001).

The influence of the sun angle and induced shadows in presence of abrupt topography could not be perceived in other areas, as it did not exceed $1 \%$ of the land cover. The change in surface area of shadows, which was induced by the presence of abrupt topography and low sun angle, was sensitive for the class of clear or deep water. Indeed, suface water occupied less than $1 \%$ of the land cover, just as much as the land area covered by shadows. Consequently, the change in the surface area of shadows induced significant change in the class of clear or deep water. Nonethelss, this bias was not critical to the study considering that this was later corrected using band ration indices. The use of bands ratios is well known to discriminate shadows due to topography (Lawrence \& Ripple, 1998).

The size categorization of reservoirs in the district was validated by the number of medium to large dams. This was confirmed by the national water authority (ZINWA), which has management responsibility of medium to large dams. It could be argued that some very small reservoirs may have been eliminated together with residual waters by the 2 pixels threshold. However, the existence or reliability of such reservoirs may not be useful as any small reservoir of a capacity less less than $24,533 \mathrm{~m}^{3}$ (that corresponds to 19 pixels of surface area) is likely to fail by May.

The number of 256 small reservoirs is higher than the 149 small reservoirs identified by DDF, or 154 small reservoirs in RDC records, or the 205 small reservoirs in ZINWA records for the whole area of Shashe, Upper 
and Lower Mzingwane subcatchments that fall under the Mzingwane catchment area. The three subcatchments cover an area that is greater than the district. Further field research may be necessary to confirm whether such difference is due to unreliability and disparate data in various organisations' records or there were non-captured small reservoirs that were finally identified. Still, the findings of the identification exercise emphasise what was discussed by Sawunyama et al. (2006) - remote sensing and GIS can be used effectively to identify small reservoirs in data scarce areas, which saves time and cost.

The study did not develop an algorithm to provide values of turbidity and chlorophyll-a based on reflectance because of lack of ancillary data on the time of satellite overpass. However, the approach used proved effective in judging the quality of the water in the reservoirs as critical or acceptable. The approach was useful to indicate if there was environmental degradation in their specific catchments.

The study confirmed that the capacity of reservoirs is more dependent on the surface area than the depth. Therefore a formula based on the area itself could provide an estimate of the capacity, as reviewed and successfully applied in Insiza district by Sawunyama et al. (2006). However, different scales in terms of the average depth of the small reservoirs, proved to be a limitation to apply the formula determined in Insiza district to Gwanda district. A model based on the shape of a pyramid was successfully used to estimate capacity of small reservoirs using remotely sensed surface area and an average depth.

The study successfully illustrated that it is possible to apply ICTs in order to generate information for effective management of small reservoirs in the Limpopo basin in Zimbabwe, where data was found to be lacking or disparate. The critical information is the location, capacity, as well as turbidity and chlorophyll-a occurrence. The study also proved that relating indices of turbidity and chlorophyll-a based on the basis of remote sensing data can be used to establish classes of severity or acceptability of turbidity and chlorophyll-a levels of small reservoirs.

Overall, the study demonstrated that ICTs can successfully be used to identify and characterise small reservoirs in the Limpopo basin in Zimbabwe. This can be used to manage available water resources for the benefit of the rural communities in the Limpopo river basin in Zimbabwe and in the entire Limpopo river basin.

\section{Acknowledgement}

The authors would like to acknowledge WaterNet and Challenge Programme on Water and Food Phase II Water Governance (L4) Project for sponsoring this study through the MSc in Integrated Water Resources Management Programme at the University of Zimbabwe.

\section{References}

Brezonik, P. M. K. D., \& Marvin, B. (2005). Landsat-based remote sensing of lake water quality characteristics, including chlorophyll and colored dissolved organic matter (CDOM). Lake and Reservoir Management, 21(4), 373-382. http://dx.doi.org/10.1080/07438140509354442

Bustamante, J., Pacios, F., Diaz-Delgado, R., \& Aragones, D. (2009). Predictive models of turbidity and water depth in the Donana marshes using Landsat TM and ETM+ images. Journal of Environmental Management, 90, 2219-2225. http://dx.doi.org/10.1016/j.jenvman.2007.08.021

Chander, G., \& Markham, B. (2003). Revised Landsat-5 TM radiometric calibration procedures and postcalibration dynamic ranges. IEEE Transactions on Geoscience and Remote Sensing, 41, 2674-2677. http://dx.doi.org/10.1109/TGRS.2003.818464

CSO. (2002). Preliminary Report, National 2002 Population Census, Central Statistical Office (CSO), Government Printers, Harare, Zimbabwe.

CTA. (2011). ICT innovation for farmers and rural communities, Spore, $\mathrm{N}^{\circ} 152$, April-May 2011, 28 pages, ISSN 1011-0054.Technical Centre for Agricultural and Rural Cooperation (CTA), Postbus 380. 6700 AJ Wageningen, The Netherlands.

De Moustier, C. (1988). State of the Art in Swath Bathymetry Systems. International Hydrographic Review LXV, (2), 25-54.

DEC. (1987). An Owners Guidance Manual For the Inspection and Maintenance of Dams in New York State, DEC Publication, Department of Environmental Conservation (DEC), Division of Water, New York State, United States of America.

Duan, H., Zhang, Y., Zhang, B., Song, K., \& Wang, Z. (2007). Assessment of Chlorophyll-a Concentration and Trophic State for Lake Chagan Using Landsat TM and Field Spectral Data. Environ Monit Assess, 129, 


\section{5-308. http://dx.doi.org/10.1007/s10661-006-9362-y}

Encyclopaedia Britannica. (2010). Encyclopaedia Britannica Ultimate Reference Suite, Encyclopædia Britannica, Chicago, United States of America.

FAO. (2011). Drought impact mitigation and prevention in the Limpopo River Basin - Chapter 3 Social, economic and policy environment, Natural Resources Management and Environment Department, http://www.fao.org/docrep/008/y5744e/y5744e09.htm

FAO, UNESCO. (2006). WRB Map of World Soil Resources, FAO. http://www.fao.org/ag/agl/agll/wrb//soilres.stm\#down, Rome.

Gupta, R. P., \& Banerji, S. (1985). Monitoring of reservoir volume using LANDSAT data. Journal of Hydrology, 77(1-4), 159-170. http://dx.doi.org/10.1016/0022-1694(85)90204-5

Hadjimitsis, D. G., \& Clayton, C. (2011). Field Spectroscopy for Assisting Water Quality Monitoring and Assessment in Water Treatment Reservoirs Using Atmospheric Corrected Satellite Remotely Sensed Imagery. Remote Sensing, 3, 362-377. http://dx.doi.org/10.3390/rs3020362

Hadjimitsis, D. G., Hadjimitsis, M. G., Clayton, C., \& Clarke, B. A. (2006). Determination of Turbidity in Kourris Dam in Cyprus Utilizing Landsat TM Remotely Sensed Data. Water Resources Management, 20, 449-465. http://dx.doi.org/10.1007/s11269-006-3089-y

Hayes, N., \& Rajao, R. (2011). Competing institutional logics and sustainable development: the case of geographic information systems in Brazil's Amazon region. Information Technology for Development, 17(1), 4-23. http://dx.doi.org/10.1080/02681102.2010.511701

Irigoien, X., \& Castel, J. (1997). Light Limitation and Distribution of Chlorophyll Pigments in a Highly Turbid Estuary: the Gironde (SW France), Estuarine. Coastal and Shelf Science, 44, 507-517. http://dx.doi.org/10.1006/ecss.1996.0132

IUSS Working Group WRB. (2006). World Reference Base for Soil Resources 2006, World Soil Resources Reports , 103, FAO, Rome.

Jansky, L., \& Uitto, J. I. (2005). Enhancing participation and governance in water resources management: Conventional Approaches and Information Technology, United Nations University Press, New York, United States of America.

Kabell, T. (1986). Assessment of design flood hydrographs. Zimbabwe Engineer, 24(1)

Kileshye, O. J. M., \& Taigbenu, A. (2009). NDVI-rainfall relationship in the Semliki watershed of the equatorial Nile. Physics and Chemistry of the Earth, 34, 711-721. http://dx.doi.org/10.1016/j.pce.2009.06.004

Koelmans, A. A., \& Lijklema, L. (1996). Fate of Nutrients and Micropollutants in Reservoirs, In Proceedings of the Workshop on Reservoir sedimentation.

Lawrence, R. L., \& Ripple, W. J. (1998). Comparisons among Vegetation Indices and Bandwise Regression in a Highly Disturbed, Heterogeneous Landscape: Mount St. Helens, Washington. Remote Sensing of Environment, 64(1), 91-102. http://dx.doi.org/10.1016/S0034-4257(97)00171-5

Lillesand, T. M., Kiefer, R. W., \& Chipman, J. W. (2004). Remote Sensing and Image Interpretation, John Wiley \& Sons, Inc., Hoboken, NJ, United States of America.

Manzungu, E., Mpho, T. J., \& Mpale-Mudanga, A. (2009). Continuing Discontinuities: Local and State Perspectives on Cattle Production and Water Management in Botswana. Water Alternatives, 2(2), 205-224.

Monaghan, R. M., Carey, P. L., Wilcock, R. J., Drewry, J. J., Houlbrooke, D. J., Quinn, J. M., \& Thorrold, B. S. (2009). Linkages between land management activities and stream water quality in a border dyke-irrigated pastoral catchment. Agriculture, Ecosystems and Environment, 129, 201-211. http://dx.doi.org/10.1016/j.agee.2008.08.017

Moore, G. K. (1980). Satellite remote sensing of water turbidity. Hydrological Sciences-Bulletin-des Sciences Hydrologiques, 25(4), 407-421. http://dx.doi.org/10.1080/02626668009491950

Moyce, W., Mangeya, P., Owen, R., \& Love, D. (2006). Alluvial aquifers in the Mzingwane catchment: Their distribution, properties, current usage and potential expansion. Physics and Chemistry of the Earth, 31, 988-994. http://dx.doi.org/10.1016/j.pce.2006.08.013

Mtisi, S., \& Nicol, A. (2003). Caught in the act: new stakeholders, decentralisation and water management processes in Zimbabwe, Research Paper 14, Sustainable Livelihoods in Southern Africa Programme, 
Institue of Development Studies, Brighton.

Mufute, N. L., Senzanje, A., \& Kaseke, E. (2008). The development of a risk of failure evaluation tool for small dams in Mzingwane Catchment, Zimbabwe. Physics and Chemistry of the Earth, 33, 926-933. http://dx.doi.org/10.1016/j.pce.2008.06.029

Mupangwa, W., Twomlow, S., \& Walker, S. (2008). The influence of conservation tillage methods on soil water regimes in semi-arid southern Zimbabwe. Physics and Chemistry of the Earth, 33, 762-767. http://dx.doi.org/10.1016/j.pce.2008.06.049

Muvundja, F. A., Pasche, N., Bugenyi, F. W. B., Isumbisho, M., Müller, B., Namugize, J.-N., Rinta, P., Schmid, M., Stierli, R., \& Wüest, A. (2009). Balancing nutrient inputs to Lake Kivu. Journal of Great Lakes Research, 35, 406-418. http://dx.doi.org/10.1016/j.jglr.2009.06.002

Naiman, R. J., \& Dudgeon, D. (2009). Global alteration of freshwaters: influences on human and environmental well-being, Ecol Res.

Nas, B., Ekercin, S., Karabörk, H., Berktay, A., \& Mulla, D. J. (2010). An Application of Landsat-5TM Image Data for Water Quality Mapping in Lake Beysehir, Turkey. Water Air Soil Pollut, 212, 183-197. http://dx.doi.org/10.1007/s11270-010-0331-2

Ouaidrari, H., \& Vermote, E. F. (1999). Operational Atmospheric Correction of Landsat TM Data. Remote Sensing of Environment, 70, 4-15. http://dx.doi.org/10.1016/S0034-4257(99)00054-1

PlanAfric. (2000). Gwanda District Integrated Rural Water Supply and Sanitation Project 1995-2000, Final Evaluation Report, Prepared for The Government of Zimbabwe and UNICEF, UNICEF, http://www.unicef.org/evaldatabase/files/2000_Zim_Gwanda_rec_386618.pdf

Raharimahefa, T., \& Kusky, T. M. (2010). Environmental Monitoring of Bombetoka Bay and the Betsiboka Estuary, Madagascar, Using Multi-temporal Satellite Data. Journal of Earth Science, 21(2), 210-226. http://dx.doi.org/10.1007/s12583-010-0019-y

Rakhmatullaev, S. (2010). Improvement of operational methods for the Assessment of the water reservoir useful Storage capacity using geoinformation systems: Case study of the Akdarya Reservoir, Samarqand Province, Uzbekistan, Sciences et Environnements (ED 304) Department in collaboration with Tashkent Institute of Irrigation and Melioration, Université de Bordeaux 1, PhD Thesis, Géosciences, Hydrosciences, Talence, France.

Rasmussen, P. P., Gray, J. R., Glysson, G. D., \& Ziegler, A. C. (2009). Guidelines and procedures for computing time-series suspended-sediment concentrations and loads from in-stream turbidity-sensor and streamflow data, U.S. Geological Survey.

Sawunyama, T. (2005). Estimation of small reservoir storage capacities in Limpopo river Basin using Geographical Information Systems (GIS) and remotely sensed surface areas: a case of Mzingwane Catchment, Department of Civil Engineering, University of Zimbabwe, Masters Thesis in Integrated Water Resources Management, Harare.

Sawunyama, T., Senzanje, A., \& Mhizha, A. (2006). Estimation of small reservoir storage capacities in Limpopo River Basin using geographical information systems (GIS) and remotely sensed surface areas: Case of Mzingwane catchment. Physics and Chemistry of the Earth, 31, 935-943. http://dx.doi.org/10.1016/j.pce.2006.08.008

Scheffer, M., S. Carpenter, J. A. Foley, C., \& Walker, B. (2001). Catastrophic shifts in ecosystems. Nature, 413 (11), 591-596. http://dx.doi.org/10.1038/35098000

Senzanje, A., Boelee, E., \& Rusere, S. (2008). Multiple use of water and water productivity of communal small dams in the Limpopo Basin, Zimbabwe. irrigation and Drainage Systems, 22, 225-237.

Senzanje, A., \& Chimbari, M. (2002). Inventory of small dams in Africa - a case study for Zimbabwe. Draft report for Water, Health and Environment, The International Water Management Institute (IWMI), P.O. Box 2075, Colombo, Sri Lanka.

Shinde, V., Tiwari, K. N., \& Singh, M. (2010). Prioritization of micro watersheds on the basis of soil erosion hazard using remote sensing and geographic information system. International Journal of Water Resources and Environmental Engineering, 2(3), 130-136.

Singh, R. B., \& Singh, A. (2004). Geospatial Information System For Hydrological Mapping Programmes, In Proceedings of the Water Resources Governance And Education In India, Balwois 2004, held in Ohrid, FY 
Republic of Macedonia, 25-29 May 2004.

Srestha, D. P., \& Zinck, J. A. (2001). Land use classification in mountainous areas: integration of image processing, digital elevation data and field knowledge (application to Nepal). International Journal of Applied Earth Observation and Geoinformation, 3(1), 78-85. http://dx.doi.org/10.1016/S0303-2434(01)85024-8

Tolk, B. L., Han, L., \& Rundquist, D. C. (2000). The impact of bottom brightness on spectral reflectance of suspended sediments. International Journal of Remote Sensing, 21(11), 2259-2268. http://dx.doi.org/10.1080/01431160050029558

UN. (2010). Gwanda District - Annual Development Plan: January 2011 - December 2011, UN (United Nations), http://ochaonline.un.org/OchaLinkClick.aspx?link=ocha\&docId=1177330.

Usali, N., \& Ismail, M. H. (2010). Use of Remote Sensing and GIS in Monitoring Water Quality. Journal of Sustainable Development, 3(3), 228-238. http://dx.doi.org/10.1016/j.agee.2008.06.004

Valentin, C., Agus, F., Alamban, R., Boosaner, A., Bricquet, J. P., Chaplot, V., ... Vadari, T. (2008). Runoff and sediment losses from 27 upland catchments in Southeast Asia: Impact of rapid land use changes and conservation practices. Agriculture, Ecosystems and Environment, 128, 225-238.

Verbyla, D. L., \& Boles, S. H. (2000). Bias in land cover change estimates due to misregistration. International Journal of Remote Sensing, 21(18), 3553-3560. http://dx.doi.org/10.1080/014311600750037570

Wainwright, D., \& Waring, T. (2004). Three domains for implementing integrated information systems: redressing the balance between technology, strategic and organisational analysis. International Journal of Information Management, 24, 329-346. http://dx.doi.org/10.1016/j.ijinfomgt.2004.04.001

Zimbabwe. (1983). An assessment of the surface water resources of Zimbabwe and guidelines for development planning, Ministry of water resources and development, Harare, Zimbabwe.

Zimbabwe. (1998). Water Act. Government of Zimbabwe, Government Printers, Harare. 